\title{
Toxoplasmosis diseminada fatal post trasplante de médula ósea en una adolescente en remisión de linfoma
}

\section{Fulminant disseminated toxoplasmosis in an adolescent with remission of lymphoma and history of bone marrow transplant.}

Pérez-García $\mathrm{M}^{1}$, de Uña-Flores $\mathrm{A}^{2}$, Cedillo-Peláez $\mathrm{C}^{3}$, López-Corella $\mathrm{E}^{4}$

\section{RESUMEN CLÍNICO}

Niña de 15 años de edad referida de su Centro de Salud a este Instituto por un cuadro de tres semanas que empezó con cefalea y mareo, edema en párpado superior derecho, diplopia y parálisis de sexto par; se agregó aumento de volumen de ambas mamas y alteración en la marcha con caídas, debilidad y parestesia de extremidad inferior izquierda.

La niña había sido sana hasta esta enfermedad, era residente de Mihuacán, Estado de México. La familia está compuesta por padres, dos hermanas de 18 y 19 años y los cuatro abuelos, todos sanos.

A su ingreso a este Instituto, 16 de enero del 2016, fue valorada por el Servicio de Neurología el que descartó un síndrome de neurona motora inferior y se consideró una radiculopatía de tipo de Guillain-Barré. La imagen de resonancia magnética (MRN) de
${ }^{1}$ Departamento de Oncología. Departamento de Radiología e Imagen.

${ }^{3}$ Laboratorio de Inmunología Experimental. Torre de Investigación.

${ }^{4}$ Departamento de Patología.

Instituto Nacional de Pediatría, México.

Recibido: 6 de octubre del 2017

Aceptado: 16 de octubre del 2017

Correspondencia

Dr. Eduardo López Corella

tarto006@gmail.com

Este artículo debe citarse como Pérez-García M, de Uña-Flores A, Cedillo-Peláez C, López-Corella E. Toxoplasmosis diseminada fatal post trasplante de médula ósea en una adolescente en remisión de linfoma. Acta Pediatr Mex. 2017;38(6):402-411. 
cráneo mostró reforzamiento del $3^{\circ}$ y $4^{\circ}$ par derecho y del $6^{\circ}$ bilateral, así como reforzamiento intenso en médula espinal ventral y en raíces de la cauda equina. Con la impresión diagnóstica de meningitis fue transferida a Infectología. Una punción lumbar del 22 de enero resultó positiva para blastos linfoides. La radiografía de tórax reveló una masa mediastinal anterior corroborada por tomografía axial computada (TAC) y la biopsia de mediastino por una incisión de Chamberlain reveló una masa mediastinal violácea y friable. La biopsia de la masa se informó como leucemia/linfoma linfoblástico de linfocitos T. La biopsia de médula ósea $(\mathrm{MO})$ fue negativa para leucemia y se encontraron nuevamente blastos en líquido cefalorraquídeo (LCR).

Se inició quimioterapia con protocolo San Judas XIIIB (vincristina, daunorrubicina, L-asparginasa, etopósido y citarabina) ${ }^{1}$ que concluyó el 13 de marzo, seguido de consolidación con metrotrexate, 6 mercaptopurina, etopósido y citarabina hasta el 14 de septiembre.

Una citología de LCR del 4 de febrero fue negativa para blastos. El manejo fue como externa y en ocasiones se ingresó por cuadros de infecciones y neutropenia, epistaxis o hemorragias petequiales y un cuadro de sepsis grave de foco abdominal con enterocolitis neutropénica; presentó dos cuadros de dolor abdominal intenso que motivó la consideración de una pancreatitis secundaria a L-asparginasa pero las enzimas pancreáticas no rebasaban los límites de referencia y no confirmaban el diagnóstico. Todos estos cuadros se resolvieron. La masa mediastinal y la infiltración a mamas ya no eran visibles en la placa de tórax. Durante su ingreso el 19 de septiembre una biopsia de MO y una citología de LCR del 27 de septiembre resultaron negativas para actividad leucémica.

Se consideró candidata a trasplante de células progenitoras hematopoyéticas; era haploidéntica a su hermana mayor con la salvedad de que esta tenía un hijo, lo que aumentaba el riesgo de enfermedad de injerto contra huésped (EICH). Recibió radioterapia como parte de la etapa de acondicionamiento y el 6 y 7 de octubre del 2016 se trasplantó con células hematopoyéticas progenitoras periféricas, con depleción in vivo con ciclofosfamida.

Los estudios de carga viral del 18 de octubre para citomegalovirus (CMV), virus de Epstein Barr (EBV), virus BK y JC resultaron negativos. Estudios para antígeno de Aspergillus de la misma fecha resultaron negativos. Los estudios inmunohematológicos para hepatitis B y C, HIV 1-2, sífilis, Chagas. Brucella y CMV fueron también negativos. Durante su internamiento se documentó hemoglobina baja de hasta $6.5 \mathrm{~g} / \mathrm{dL}$ con 393-361 x10/6 eritrocitos por microlitro, leucocitos de $3 \mathrm{mil} / \mathrm{mcl}$ y plaquetopenia de 58 mil y hasta $7 \mathrm{mil} / \mathrm{mcl}$. Los triglicéridos se cuantificaron en $321 \mathrm{mg} / \mathrm{dL}$. Una biopsia de piel del 27 de octubre se informó como compatible con $\mathrm{EICH}$. Se egresó en condiciones satisfactorias el 4 de noviembre con los diagnósticos de linfoma linfoblástico T estadio IV por infiltración a SNC y MO, actualmente en remisión CR1 (primera remisión completa), bajo inmunosupresión con tacrolimus y micofenolato.

Ocho días después, el 12 de noviembre, se presentó en el Servicio de Urgencias hipotensa y con extremidades frías. Había empezado cuatro días antes con un cuadro de evacuaciones diarreicas, sin fiebre, dolor, náusea o vómito, que evolucionó a disnea y polipnea. Se recibió hipotensa $(92 / 63 \mathrm{~mm} / \mathrm{Hg})$, taquicárdica (160 latidos por minuto), con polipnea (38 respiraciones por minuto) con desequilibrio hidroelectrolítico y acidosis metabólica $(\mathrm{pH} 7.17$, PCO2 $33.31 \mathrm{~mm} / \mathrm{Hg}$, HCO3 12mmol/L, Sat O2 $32.7 \%$, BE $-15.2 \mathrm{mmol} / \mathrm{L}$, glucosa $143 \mathrm{mg} / \mathrm{dL}$, lactado $4.18 \mathrm{mmol} / \mathrm{L}$ ) y datos clínicos de choque. Tras varios intentos de venoclisis y osteoclisis se logró colocar venoclisis en yugular izquierda 
con colocación de catéter de presión venosa central, con mejoría parcial de la sintomatología. La radiografía de tórax mostró un neumotórax derecho a tensión y se aplicó un sello pleural. Siguió con deterioro electrolítico, presentaba acidosis metabólica e hiperlactatemia y luego deterioro ventilatorio y hemodinámico hasta el paro cardiorrespiratorio. Falleció a las 18:39 horas del mismo día 12 de noviembre.

La familia autorizó el estudio de autopsia, solicitada por el Dr. Ramiro García del Servicio de Urgencias, con la restricción de que no se autorizó estudio del cráneo.

\section{DIAGNÓSTICOS CLÍNICOS DE EGRESO}

- Síndrome de dificultad respiratoria.

- Neumonía de microorganismo no especificado.

- Linfoma linfoblástico de células T, estadio IV.

\section{COMENTARIO RADIOLÓGICO (Dr. de Uña)}

A la paciente se le realizaron estudios iniciales de la placa radiográfica de tórax (Figura 1) en la que se aprecia con masa mediastinal en mamas. Se inició abordaje radiológico con estudio de ultrasonografía pélvica y de mamas, así como tomografía computada mediastinal y abdómino pélvica donde se corrobora lesión tumoral en diversos niveles: mediastino, mamas y en pelvis a nivel parametrial, que el estudio de PET CT corroboró con un alto metabolismo de hasta 16 de SUVmax (Figura 2).

Los síntomas neurológicos obligaron a complementar con estudio de resonancia magnética de encéfalo y neuroeje contrastada con gadolinio, donde se demostró infiltración al sistema nervioso

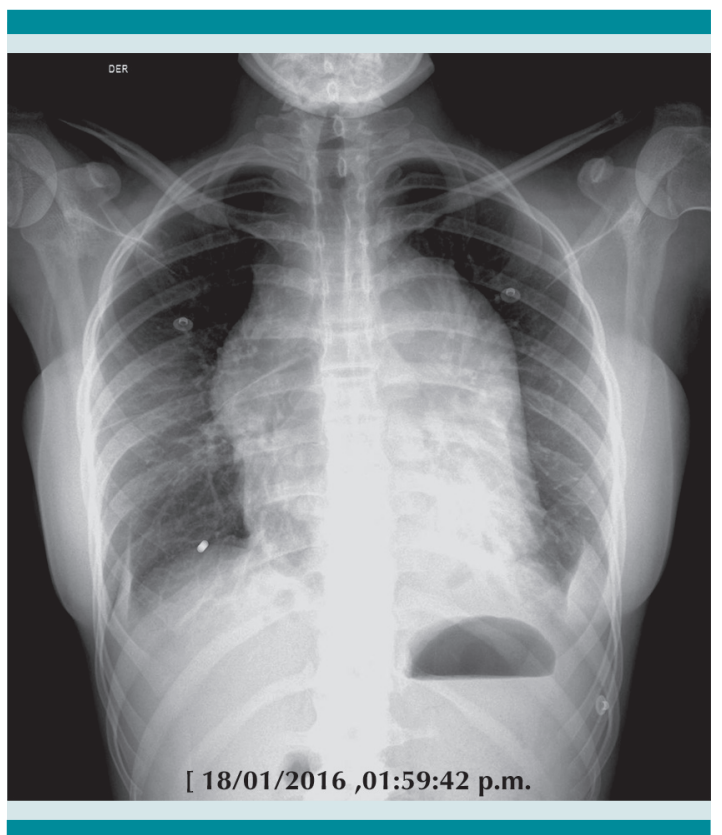

Figura 1. Estudio radiográfico de tele de tórax donde se demuestra crecimiento mediastinal a expensas de mediastino medio y anterior, así como crecimiento bilateral de glándulas mamarias.

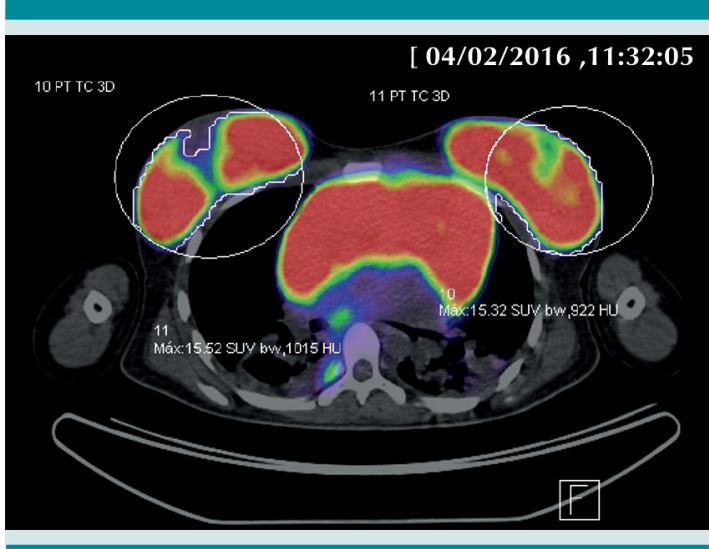

Figura 2. Estudio de PET CT con 18FDG con intensa captación del radiotrazador en mediastino y mamas con SUVmax de hasta 16.

central de tipo leptomeníngeo, caracterizada por engrosamiento y reforzamiento de pares craneales y de la cauda equina (Figuras 3 y 4) que 


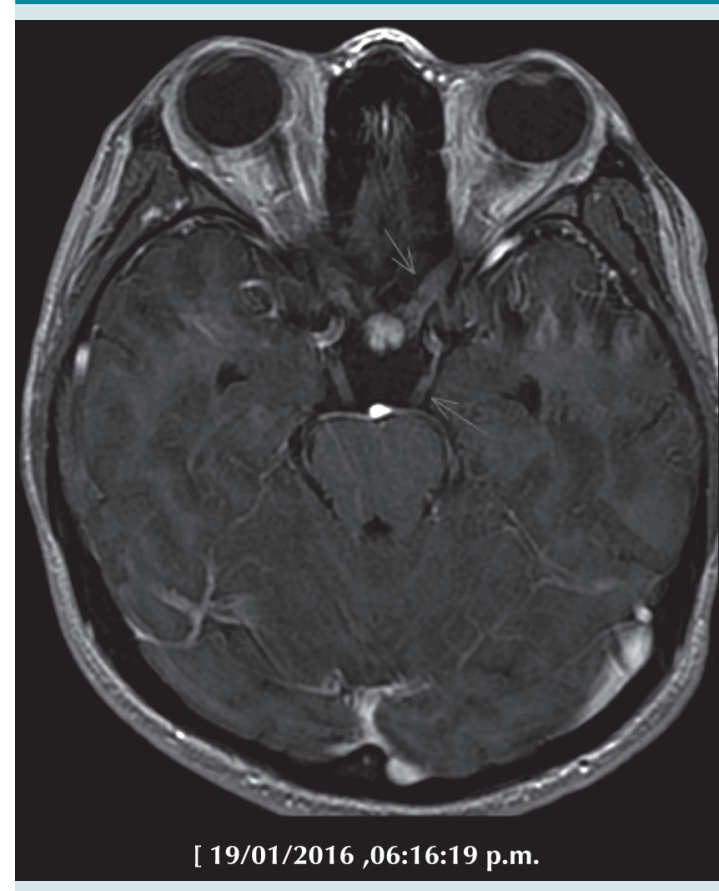

Figura 3. Imagen de resonancia magnética en secuencia SPGR, ponderada en T1 contrastada con gadolinio demostrándose el engrosamiento y reforzamiento de los nervios craneales ( $2^{\circ}$ y $3^{\circ}$ en esta imagen).

diversos autores documentan entre un 2 y $27 \%$ según la agresividad en el linfoma no Hodgkin y solo menos del $0.5 \%$ en linfoma de Hodgkin. ${ }^{2}$

Con el tratamiento instituido, la niña entró en remisión y desparecieron la masa mediastinal y los datos de afección mamaria (Figura 5). La autopsia aclara el cuadro final con una complicación pulmonar por Toxoplasma gondii; es una complicación rara de la inmunosupresión; sin embargo, de los parásitos intracelulares es el más usual. Se describe en el paciente inmuno comprometido con opacidades nodulares gruesas o con un patrón retículo nodular grueso, difuso, como el presentado finalmente por nuestra paciente, con una progresión rápida (Figura 6).

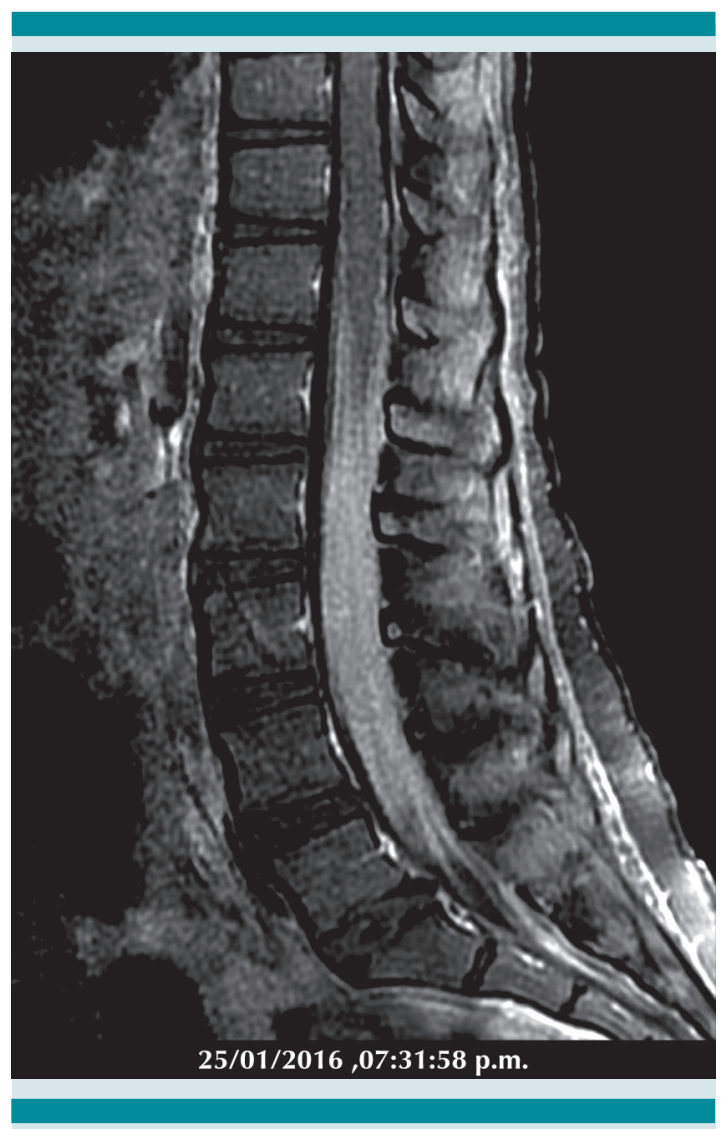

Figura 4. Imagen de resonancia magnética de neuroeje en secuencia ponderada en T1 con saturación grasa contrastada con gadolinio que demuestra engrosamiento y reforzamiento de las raíces nerviosas de la cauda equina.

\section{COMENTARIO ANATOMOPATOLÓGICO (Dr. López Corella)}

El tejido obtenido en la biopsia mediastinal era de un linfoma con núcleos moderadamente pleomórficos, redondeados o lobulados, de cromatina fina casi sin nucléolos y con muy escaso citoplasma. De un amplio elenco de reacciones de inmunohistoquímica destaca la positividad a TdT y CD3 que lo define como un linfoma/ leucemia linfoblástico preT con un alto índice de proliferación (Ki67 de 90\%) (Figura 7). 


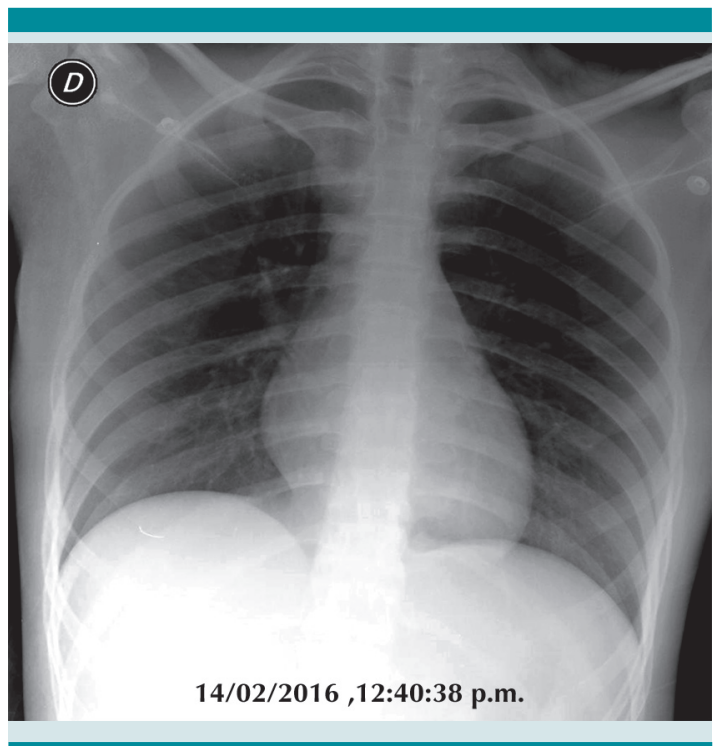

Figura 5. A casi un mes se demuestra resolución prácticamente total de los crecimientos mediastinales así como de la mama con un estudio de tele de tórax normal.

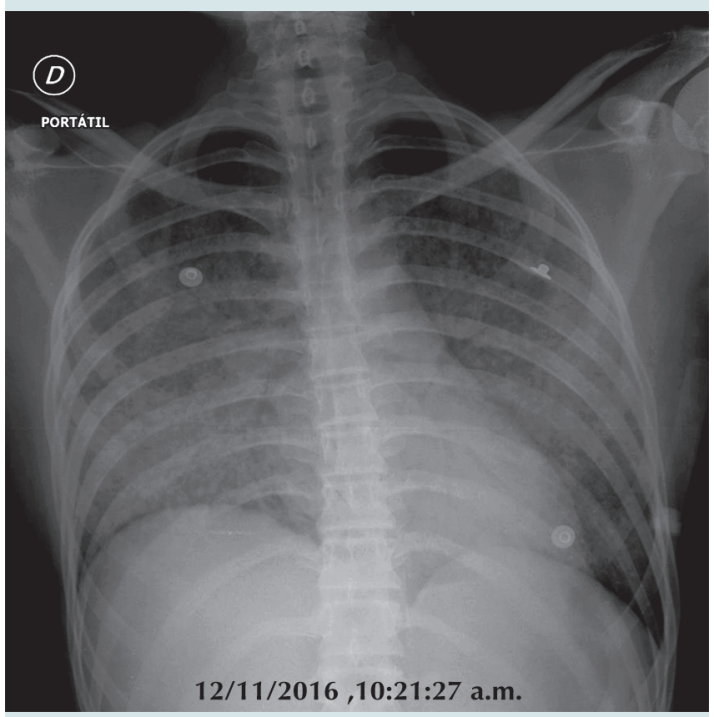

Figura 6. Estudio radiográfico de tórax portátil demostrándose radio opacidad pulmonar con un patrón retículo nodular denso, bilateral y simétrico con presencia de broncograma aéreo

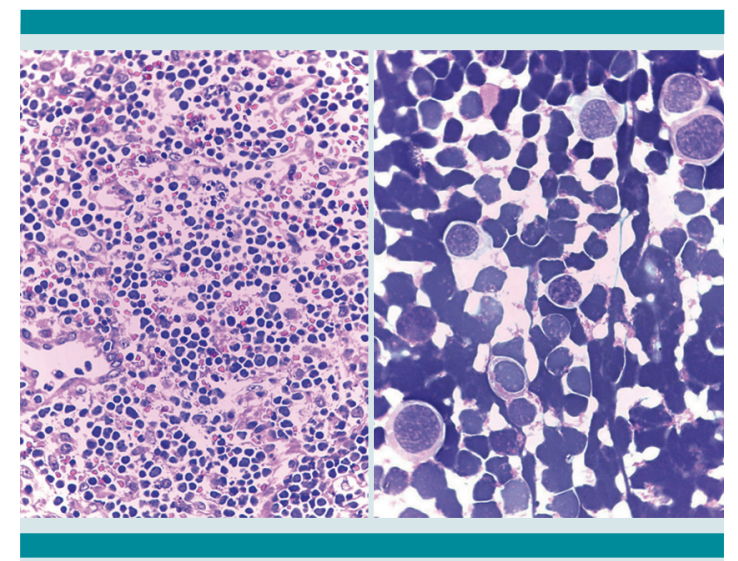

Figura 7. Linfoma mediastinal. Biopsia de mediastino (izquierda) que muestra el tumor formado por células linfoides de aspecto blástico. Líquido cefalorraquídeo (derecha) con numerosos blastos linfodies sobre un fondo de eritrocitos.

La paciente fue llevada a remisión y a trasplante de células hematopoyéticas (TCPH); durante este lapso estuvo con altibajos pero más o menos estable en régimen de mantenimiento. $\mathrm{Al}$ mes post trasplante presentó un cuadro de cuatro o cinco días de evolución de profundo deterioro que la condujo a la muerte.

En la autopsia no se encontró linfoma. Lo que más Ilamó la atención durante la autopsia fue la presencia de frecuentes granulaciones dispersas en los pulmones, de situación subpleural y parenquimatosa. Medían de 2 a 4 milímetros y tenían aspecto de granulomas. Con el microscopio se veía que no eran granulomas sino focos de necrosis, con componentes de daño alveolar agudo, rodeados de alveolos bien ventilados (Figura 8). En el seno de la necrosis, se identificaban numerosos organismos con morfología de Toxoplasma, tanto en forma de pseudoquistes (una célula infectada repleta de taquizoitos) o de taquizoitos dispersos, una vez que la célula infectada ha estallado (Figura 9). Tanto la morfología de los parásitos como el contexto clínico y tisular apoyan fuertemente el diagnóstico de Toxoplasma pero otros microorganismos (Leish- 


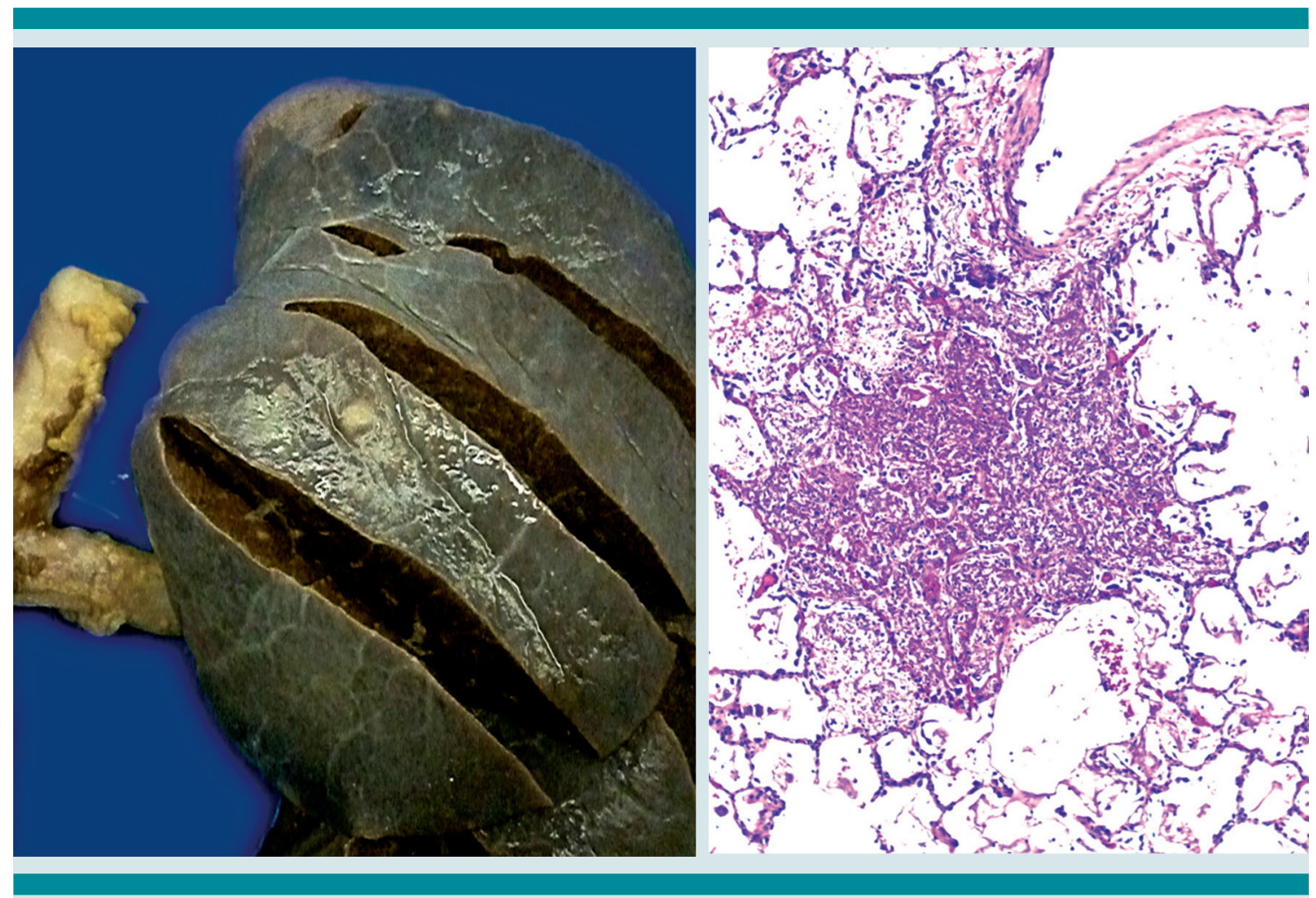

Figura 8. En los pulmones (izquierda) hay numerosas granulaciones subpleurales y parenquimatosas. Al examen microscópico (derecha) se aprecian focos de necrosis, con componentes de daño alveolar agudo, rodeados de alveolos bien ventilados.

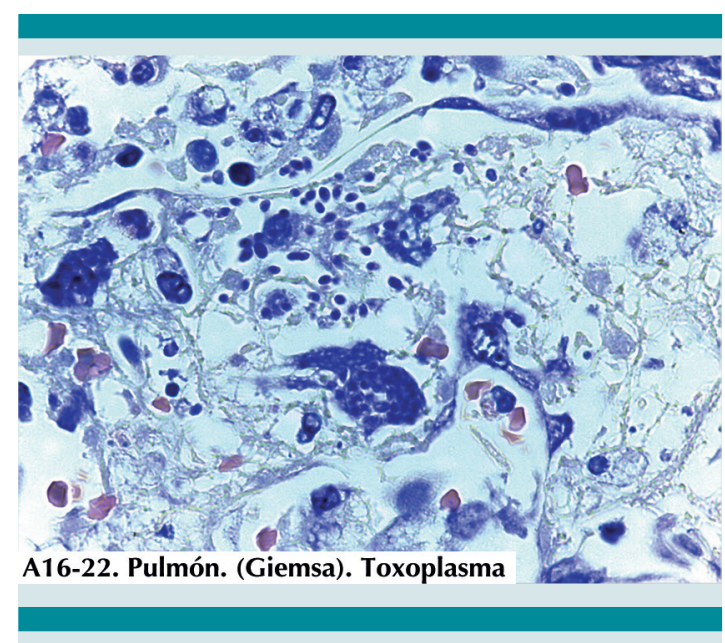

Figura 9. En los focos de necrosis en pulmón hay numerosos taquizoitos de Toxoplasma tanto dentro de pseudoquistes como dispersos en la necrosis. (Giemsa). mania, Sarcocystis, Besnoitia, Nosema, levaduras ovales y quizás otros) pueden plantear dudas diagnósticas en situaciones especiales. Técnicas de inmunohistoquímica (Figura 10) y de biología molecular que expone más adelante el Dr. Carlos Cedillo aportan una certeza diagnóstica. Pseudoquistes y taquizoitos libres se encontraron en múltiples focos necróticos en médula ósea, en úlceras en estómago y en colon, en focos de necrosis en páncreas y en hígado.

Llamó la atención la presencia de hemofagocitosis, con linfocitos, eritrocitos y restos celulares en el interior de macrófagos; se identificaron en médula ósea, en bazo y en hígado (Figura 11). Nunca se documentó hepato o esplenomegalia, ni en vida ni en la autopsia, pero la niña pre- 


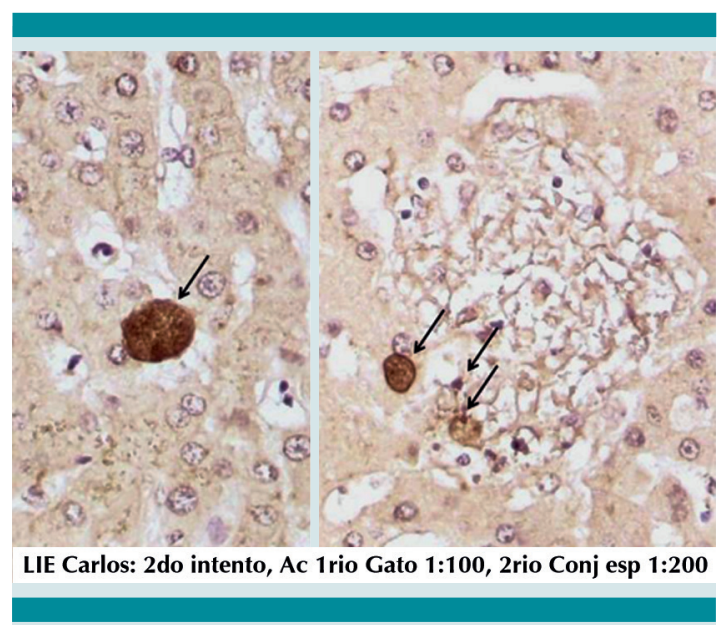

Figura 10. La inmunohistoquímica con anticuerpo específico anti Toxoplasma revela la presencia de pseudoquistes, en este caso en los focos de necrosis en hígado (Cortesía Dr. Carlos Cedillo).

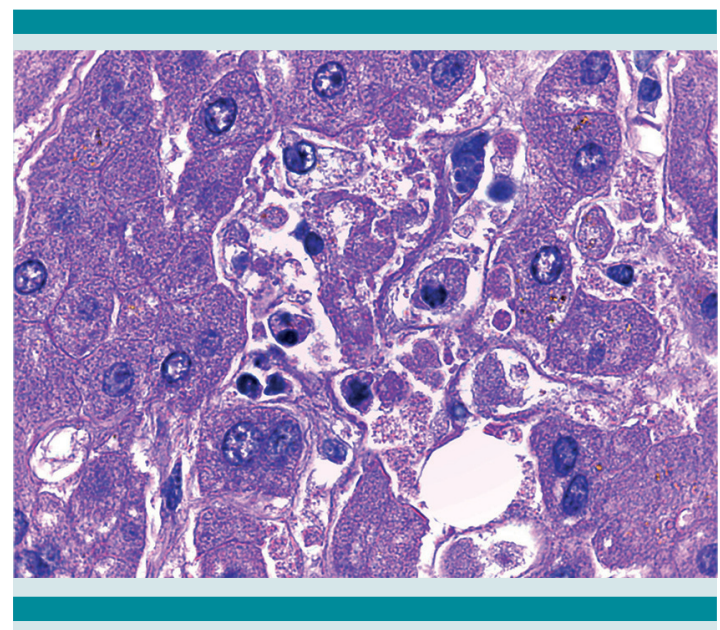

Figura 11. En un foco de necrosis en hígado se identifica un pseudoquiste de con taquizoitos (arriba en medio) y macrófagos con restos celulares fagocitados.

sentó fiebre, tiene pancitopenia y elevación de los triglicéridos; esto integra razonablemente un síndrome hemofagocítico, que se ha descrito en pacientes con trasplante de médula ósea que desarrollan una toxoplasmosis. ${ }^{3}$ Sin embargo, esto pasó inadvertido dado el estado crítico de la paciente en las pocas horas que estuvo con nosotros en su cuadro final.
Este caso reitera la importancia y, más aún, la necesidad del estudio de autopsia ante un contexto clínico complicado. ${ }^{4}$ La paciente murió con el diagnóstico clínico de infección por microorganismo no identificado. Se buscó intencionadamente y no se encontró evidencia de infección por citomegalovirus, Chagas, Brucella, sífilis, HIV y hepatitis B y C pero no se hizo serología para toxoplasmosis. La autopsia en este caso indica otro posible germen que hay que tener en cuenta al enfrentar un cuadro infeccioso en un paciente inmunocomprometido.

\section{COMENTARIO DE PARASITOLOGÍA Y BIOLOGÍA MOLECULAR (Dr. Cedillo Peláez)}

Para la confirmación del diagnóstico anatomopatológico de toxoplasmosis, se llevó a cabo la extracción de DNA a partir de secciones de tejido pulmonar del presente caso, utilizando un estuche comercial (QIAGEN) siguiendo las instrucciones del fabricante con ligeras modificaciones, llevando a cabo la digestión del tejido con proteinasa $\mathrm{K}$, la precipitación del DNA con isopropanol y su purificación con etanol.

Una vez extraído el DNA, se llevó a cabo su diagnóstico molecular utilizando como blanco la región repetitiva de 529 pb, la cual es especifica de $T$. gondii, realizando un ensayo de PCR punto final. La muestra del caso se corrió a la par con muestras previamente positivas a $T$. gondii, previamente diagnosticadas con la misma metodología, incluyendo como controles positivos, DNA de las cepas de referencia RH y Me 49, y como control negativo se incluyo una muestra sin DNA, sustituyéndola por agua. Los productos de amplificación obtenidos se visualizaron en un gel de agarosa al $1.5 \%$ teñido con bromuro de etidio.

La muestra de tejido pulmonar así como las de los tejidos de referencia resultaron positivas a la amplificación por PCR apreciándose bandas en el peso esperado similares a los controles positivos (Figura 12). 


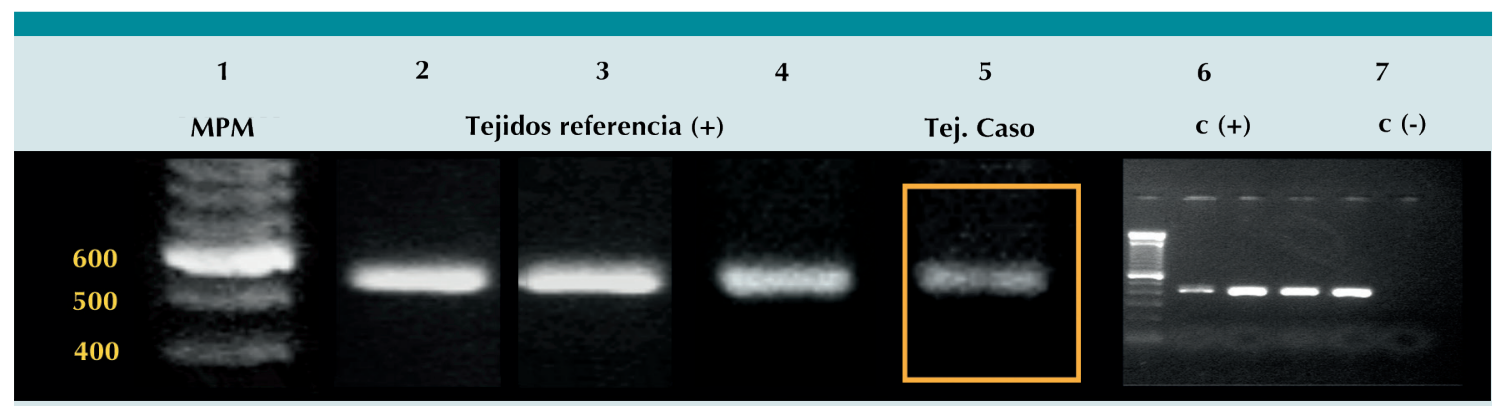

Gel de agarosa $1.5 \%$, teñido con bromuro de etidio

Figura 12. Gel de agarosa observándose productos de amplificación de PCR para la región repetitiva de 529 pb, específica de Toxoplasma gondii. Se observa en el carril 1, marcador de peso molecular (MPM); carriles 2 y 3 , tejidos de ratones inoculados con T. gondii; carril 4, tejido de perro con infección natural por T. gondii; carril 5, tejido pulmonar del presente caso, apreciándose una banda tenue bien definida, a la altura del peso esperado (529 pb), similar a las muestras de referencia; carriles 6 y 7 , controles positivo (cepa RH de T. gondii) y negativo (agua).

\section{COMENTARIO CLÍNICO Y RECAPITULACIÓN (Dr. Pérez García)}

Estamos ante una adolescente que presentó un cuadro abigarrado con alteraciones neurológicas de aparición súbita y que sugirió afección de pares craneales y espinal. Se agregaba a eso aumento de tamaño de ambas mamas que no incidió mucho en el abordaje clínico inicial ni a su llegada con nosotros.

Al momento de su ingreso, fue vista por Neurología y al considerar que se trataba de un cuadro agudo que sugería un proceso inflamatorio y objeto de manejo inmediato se transfirió al Servicio de Infectología con el diagnóstico de presunción de meningitis. Los estudios de imagen, como ya desglosó el Dr. de Uña, muy pronto esclarecieron la naturaleza del problema. La resonancia magnética reveló alteraciones en pares craneales y en médula espinal y la placa de tórax documentó la hipertrofia mamaria y mostró una gran masa en mediastino anterior y medio.

Este hallazgo inesperado obliga considerar las posibilidades de masas mediastinales anteriores en la infancia y la adolescencia: linfomas, teratomas y otros tumores germinales, hiperplasias y quistes de timo, bocio intratorácico y timoma. La homogeneidad de la masa militaba en contra de teratoma, que suele ser heterogéneo y a menudo con calcificaciones, y orienta hacia un tumor sólido con un linfoma como primera posibilidad por su frecuencia. La masa era grande y se extendía al mediastino medio, cosa que suelen hacer los linfomas; en principio obligaría a considerar las posibilidades propias de esa topografía como tuberculosis y sarcoidosis pero parecen quedar fuera del contexto clínico.

Aún antes de recurrir al diagnóstico anatomopatológico podemos discurrir que nuestra primera posibilidad es un linfoma, y dada la aparente ausencia de adenopatías y la evidencia de infiltración al sistema nervioso central, se trata de un linfoma no Hodgkin. De estos, la presentación como masa mediastinal anterior conduce como primera opción a un linfoma linfoblástico de precursores de fenotipo T. Esto en contraste con otros linfomas frecuentes en los niños: el linfoma de Burkitt o los linfomas difusos de células grandes $B$, que suelen dar masas abdominales o 
en anillo de Waldeyer, el linfoma anaplásico de células grandes que afecta ganglios, hueso o piel y el linfoma linfoblástico de precursores B que suele producir masa ganglionares o cutáneas. Ciertamente otros linfomas, más identificados con la edad adulta, pueden afectar al paciente pediátrico pero lo hacen con muchísima menos frecuencia. Entre estos, podemos listar el otro linfoma que afecta mediastino en la edad pediátrica, el linfoma B primario mediastinal, los linfomas sinonasales de células T/NK, los linfomas foliculares, los MALT y los del manto, todos ellos muy raros en esta edad. Pero los eventos raros también suceden, si bien con menos frecuencia que los frecuentes, y todo lo anteriormente expuesto es un ejercicio de conjeturas que nos sirve como una estrategia para abordar el problema pero precisa del diagnóstico anatomopatológico para concretarse.

La presencia de blastos en el líquido de punción lumbar, sin datos de proceso inflamatorio, condujo de inmediato a una biopsia de mediastino que reveló la presencia de un linfoma linfoblástico de precursores $T$ con lo que, a una semana de su ingreso, todo cae en su sitio para un diagnóstico integral; tenemos explicación desde luego, para la masa mediastinal, la presencia de blastos en líquido cefalorraquídeo es consonante con la afección de pares craneales y paraplegia, manifestaciones reconocidas de estos linfomas y la hipertrofia mamaria se explica sin mayor problema como manifestación de infiltración por el linfoma. La médula ósea, negativa para infiltración, nos afirma que se trata no de una leucemia linfoblástica sino de un linfoma linfoblástico pre T.

Esto condujo de inmediato a la instalación de un esquema de quimioterapia para linfoma de alto riesgo como corresponde al tipo histológico y a su extensión en sistema nervioso y en mamas. Se logró la remisión; la masa mediastinal desapareció así como las manifestaciones neurológicas y la hipertrofia mamaria. Durante el periodo de consolidación nuestra paciente estuvo siete meses sin evidencia de actividad neoplásica, con LCR y médulas óseas negativas y con complicaciones atribuibles a efectos de la quimioterapia y que fueron resueltos.

Por tratarse de un linfoma de fenotipo T, se consideró candidata a trasplante de médula ósea (trasplante de células progenitoras hematopoyéticas, TCPH) en esta primera remisión. Esto a diferencia de los pacientes con linfomas de fenotipo B en los cuales se suele indicar después de la primera recaída. Entró al programa de trasplante con las medidas de acondicionamiento conforme al protocolo y se tomaron todas las precauciones para evitar hasta lo posible las complicaciones infecciosas del estado de inmunosupresión. Las pesquisas de carga viral y serología para una diversidad de gérmenes resultaron negativas. La hermana haploidéntica fue la donadora del trasplante, la previsible aparición de EICH fue manejada y nuestra paciente estuvo bien durante poco más de un mes.

El cuadro final fue inesperado, cuatro días de manifestaciones gastroenterales que rápidamente evolucionaron con fiebre, síntomas respiratorios y ataque al estado general y falleció horas después de llegar a nuestro Instituto en estado de choque. Nuestra impresión era que se trataba de un choque séptico por un agente infeccioso que no habíamos identificado.

La autopsia nos aclara la naturaleza de la infección. Tenemos la evidencia de una toxoplasmosis diseminada con lesiones ulceradas en tubo digestivo, focos de necrosis en hígado y en páncreas y una afección masiva en pulmón y en médula ósea. No se precisó el mecanismo de la infección en esta paciente. Puede tratarse de la reactivación de una infección latente o haberse infectado con el trasplante; el determinar el estado serológico de la hermana donadora podría 
aclarar esta incógnita. La información que aporta la autopsia nos sugiere la conveniencia de revisar e incluir a Toxoplasma en el ya amplio catálogo de gérmenes que intentamos identificar para establecer profilaxis en un paciente que vamos a someter a inmunosupresión. La prevalencia de este microorganismo en nuestro país no es despreciable y es probable que esté subdiagnosticado. Caballero-Ortega y colaboradores ${ }^{5}$ compararon la prevalencia y distribución nacional de la toxoplasmosis humana en México, mediante el análisis de sueros de la Encuesta Nacional de Salud 2000 (ENSA-2000) y de la Encuesta Nacional de Salud y Nutrición (ENSAUT-2006). La prevalencia nacional se calculó en 40.0 y $43.9 \%$ para el año 2000 y para el 2006, respectivamente. Dicha prevalencia fue mayor en las costas en comparación con el centro y norte del país, en ambas encuestas. Este caso, sin la autopsia, hubiera quedado como "por germen no identificado".

\section{DIAGNÓSTICOS FINALES}

- Linfoma linfoblástico preT, con masa mediastinal, tratado, sin enfermedad residual.
- (Historia de trasplante de células progenitoras hematopoyéticas, 1 mes)

- Toxoplasmosis diseminada.

- Síndrome hemofagocítico.

\section{REFERENCIAS}

1. Pui C-H, Sandlund JT, Pei D. Improved outcome for children with acute lymphoblastic leukemia: results of Total Therapy Study XIIIB at St. Jude Children's Research Hospital. Blood 2004;104:2690-2696.

2. Faser RS, Paré PD. Diagnóstico en las enfermedades del tórax. 4a edición. Vol II. Editorial Médica Panamericana. Argentina. 2002. pag. 1027-1029.

3. Duband S, Cornillon J, Tavernier E, Dumollard J-M, Guyuotat $D$, Péoc'h M. Toxoplasmosis with hemophagocytic syndrome after bone marrow transplantation: diagnosis at autopsy. Transpl Infect Dis. 2008 Oct;10:372-4.

4. De León Bojorge B, Ridaura Sanz C. Toxoplasmosis en niños. Informe de seis casos de autopsia. Acta Pediatr Mex. 1999;20:187-194.

5. Caballero-Ortega H, Uribe-Salas FJ, Conde-González JC, Cedillo-Peláez C, Vargas-Villavicencio JA, Luna Pastén H, Cañedo Solares I, Ortiz Alegría LB, Correa C. Seroprevalence and national distribution of human toxoplasmosis in Mexico: analysis of the 2000 and 2006 National Health Surveys. Trans Roy Soc Trop Med Hyg 2012;106:653-659. 